\title{
Wird heute ein guter Tag sein?
}

\author{
Zwei Bücher zu einem Thema, das unsere Gesellschaft vor gewaltige Herausforde- \\ rungen stellt: Altersdemenz. Das eine zeigt anhand von Fallbeispielen die Komplexität \\ von Umgang und Pflege, das andere hinterfragt die sogenannte «Würde-Rhetorik».
}

\section{Wird heute ein guter Tag sein?}

Das fragt sich die Ehefrau eines Versicherungsdirektors mit Frontalhirndemenz. Von dieser Patientengeschichte aus einem Pflegeheim stammt der Titel des Buches von Christoph Held. Mit seinen «Erzählungen aus dem Pflegeheim», so der Untertitel, ist dem geriatrisch tätigen Psychiater und Heimarzt beim stadtärztlichen Dienst Zürich ein hervorragender Beitrag zum Schicksal fortgeschrittener Demenzkranker gelungen. Der Dozent an Fachhochschulen erhielt 2006 den Schweizerischen Alzheimerpreis für seine Verdienste als Experte und Buchautor.

In einer einfachen Sprache gelingt ihm mit sieben Fallbeispielen eine eindrückliche Einführung in die Komplexität pflegebedürftiger Menschen. Bereits heute leiden in den Pflegeheimen grosser Schweizer Städte mehr als zwei Drittel an einer fortgeschrittenen Demenz, verursacht durch mehrfache Hirnschläge, die Parkinson- oder, am häufigsten, durch die Alzheimerkrankheit. Nüchtern, präzise und einfühlsam erzählt er von seinen ärztlichen Erfahrungen. 100 Jahre nach Alois Alzheimer sind die Fortschritte bescheiden. Held zitiert den britischen Arzt Tom Kitwood, der von einer guten Pflege fordert, dass nicht die neurologischen Behinderungen, sondern das Persönliche der demenzkranken Menschen im Mittelpunkt stehen soll. Gewiss bleiben die Erkrankten zentral wichtig und deren Krankheitsgeschichten lassen nichts an medizinischer Genauigkeit vermissen.

Doch die wahren Helden sind hier die Pflegenden, Männer und Frauen aus über 12 Nationen, die uns als Persönlichkeiten überraschen, berühren und ans Herz

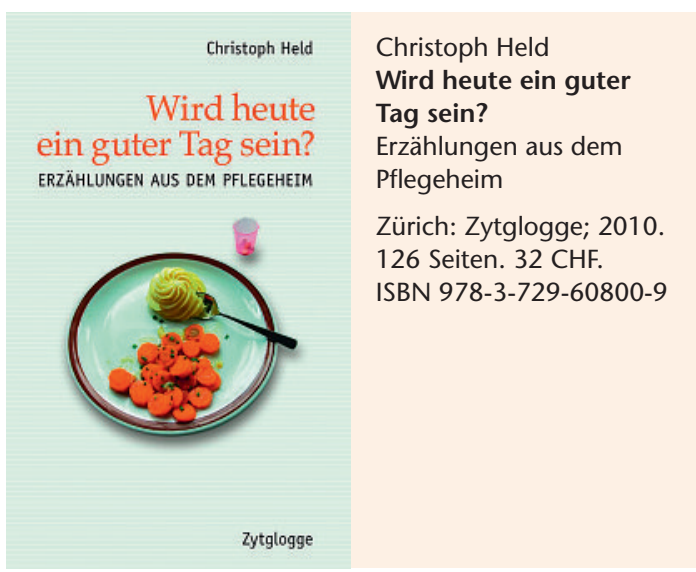

wachsen. Ihre Motive kommen zur Sprache, aber auch Spannungen unter Nationen und Geschlechtern und die veränderten Erwartungen an einen schwierigen Beruf. Eine Köchin erinnert mit ihrer Kompetenz und Empathie daran, wie bedeutend für verwirrte Patienten das Erinnern an Düfte und Gerüche aus früherer Zeit ist, das Riechen, Sehen, Beissen, Kauen und Schlucken. Die Angehörigen werden nicht vergessen, weder die überfordert Abwesenden noch jene, die Held als «Schattenbewohner unserer Heime» bezeichnet. Nicht einfach nur Besucher, sondern aktive Mitarbeiter mit einer oft engen Beziehung zum Personal.

Dem heiklen Thema der Sterbehilfe weicht Held nicht aus. Zwei bis drei Mal im Jahr werde diese Dienstleistung in Anspruch genommen. Das geschilderte Beispiel könnte man als misslungenen Start aus der Anfangszeit bezeichnen, in dem eine unbequeme Schwester «auf die Reste unserer früheren Pflegeheimkultur» pocht. Ein Einzelfall, der - detailliert und schonungslos geschildert - an die unveränderte Problematik des Würde-Begriffes erinnert. Ein sehr lesenswertes Buch. Für alle in Pflegeheimen Tätigen ein Muss.

\section{Missbrauchte Götter}

Die zunehmende Anzahl demenzkranker Menschen stellt unsere Gesellschaft vor gewaltige Herausforderungen. Wie immer bei existentiellen Problemen wird dabei an die Menschenwürde appelliert. Doch was bringt uns diese Würde-Rhetorik? «Wer sich als Hüter der Menschenwürde inszeniert, macht es sich insofern bequem: Er hat gleichsam das Heilige, Auratisierte, vorstaatlich Ewige auf seiner Seite», so der protestan-

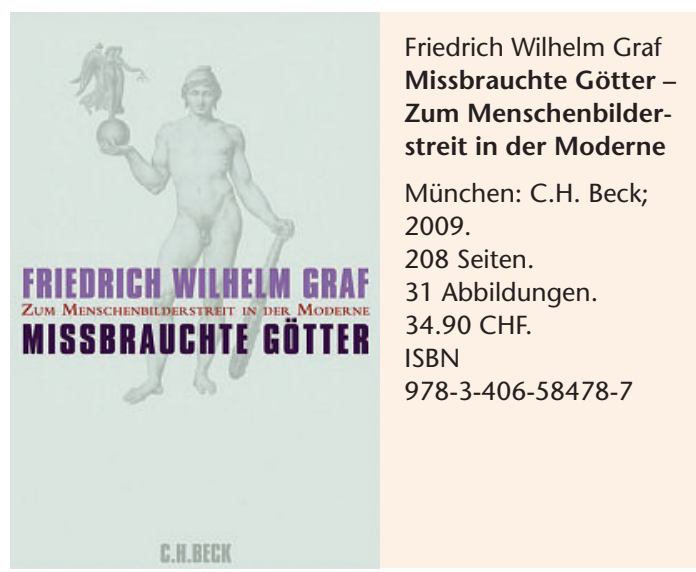


tische Theologe Friedrich Wilhelm Graf in seinem Buch «Missbrauchte Götter - Zum Menschenbilderstreit in der Moderne». Der Professor für systematische Theologie und Ethik an der Universität München liefert keine Patentrezepte. Seine klugen Ausführungen bieten eine grundlegende Analyse der vielbeschworenen Menschenbilder aktueller Kulturkämpfe. Scharfsinnig und kenntnisreich zerpflückt er ironisch die Argumente der Politiker, Juristen, Ethiker und Theologen, die sich in unseren Breiten wieder zunehmend auf ein «ideenpolitisches Privateigentum der Christen» berufen. Graf kritisiert biologistische Konzepte ebenso wie klerikale Diskurspolizisten, die mit viel Einfluss im politischen Alltag die alleinige Deutungskompetenz anstreben.
Sein hervorragend illustriertes Werk ist für Interessierte eine unverzichtbare historische Einführung in die Entwicklung der heutigen Debatten zugrunde liegenden Gottes- und Menschenbilder unserer christlich-konfessionell geprägten Kultur, ohne dabei die jüdischen und islamischen Wurzeln auszulassen. Wer moralische Arroganz vermeiden will, tut gut daran, sich mit religiösen Symbolsprachen auseinanderzusetzen. Kein leicht zu lesender, aber ein äusserst anregender und hilfreicher Beitrag zu einer vertieften Würde-Diskussion, die auch über die Zukunft unsere Pflegepraxis entscheiden wird. 